\title{
Análisis de rasgos lingüísticos en el texto andaluz La infancia de Jesu-Christo desde una perspectiva socio-histórica y cultural ${ }^{*}$
}

\author{
AIDA FABIOLA GÁMEZ MILLÁN*** \\ g.fabis@hotmail.com \\ MAYERLY AGÓN ARIZA*** \\ mayita0783@hotmail.com
}

Recepción: 15 de febrero de 2014

Aprobación: 14 de mayo de 2014

Forma de citar este artículo: Gámez Millán, A., \& Agón Ariza, M. (2014). Análisis de rasgos lingüísticos en el texto andaluz La infancia de Jesu-Christo desde una perspectiva sociohistórica y cultural. Cuadernos de Lingüística Hispánica, 25, 123-142. Tunja: Uptc.

\footnotetext{
* Artículo de investigación.

** Licenciada en Humanidades. Colegio Integrado Roel y Velasco, Aguada - Santander.

*** Licenciada en Humanidades. Colegio Integrado Roel y Velasco, Aguada - Santander.
} 


\title{
Resumen
}

Este artículo muestra el análisis lingüístico de un texto del siglo XVII intitulado La Infancia de Jesu-Christo, de Gaspar Fernández y Ávila, mediante la identificación de los rasgos semánticos, morfológicos, léxicos y sintácticos del dialecto andaluz, desde una mirada sociohistórica y cultural del pueblo andaluz. A manera de preámbulo de dicho análisis, se exponen algunos aspectos geográficos, históricos y lingüísticos en los que se origina el dialecto andaluz; se determinan los rasgos fonético-fonológicos que caracterizan el habla andaluza; se dan a conocer las influencias de otras lenguas en ese dialecto, a través del análisis léxico-semántico del mismo; se identifica su morfosintaxis, específicamente, sus diferencias y semejanzas con el español estándar; y se establece, mediante el análisis textual, las marcas de coherencia e ideología en el texto.

Palabras Clave: dialecto andaluz, nivel fonético-fonológico, nivel morfosintáctico, nivel léxico-semántico.

\section{Analysis of the linguistic features of the Andaluz text La infancia de Jesu-Christo from a sociohistorical and cultural perspective}

\begin{abstract}
This article shows a linguistic analysis of a XVII century text entitled La infancia de Jesu-Christo, written by Gaspar Fernández and Ávila. The analysis was carried out through the identification of semantic, morphological, lexical and syntactic features of the Andalusian dialect, within a sociohistorical and cultural view of the Andalusian people. As a preamble to this analysis, some geographical, historical and linguistic aspects of the origin of the Andalusian dialect are exposed; the phonetic and phonological features of Andalusian speech are determined; the influence of other languages in this dialect are presented through lexical-semantic analysis; its morphosyntax is identified, specifically, its differences and similitudes with standard Spanish, and text analysis enables the establishment of the coherence and ideological markers in the text.
\end{abstract}

Keywords: Andalusian dialect, phonetic-phonological level, morphosyntactic level, lexical-semantic level. 


\section{Analyse des traits linguistiques dans le texte andalous La infancia} de Jesu-Christo à partir d'une perspective sociohistorique et culturelle

\section{Résumé}

Cet article montre l'analyse linguistique d'un texte du XVIIème siècle intitulé $L a$ Infancia de Jesu-Christo, de Gaspar Fernández y Ávila, à travers l'identification des traits sémantiques, morphologiques, lexicaux et syntaxiques du dialecte andalous, à partir d'un regard sociohistorique et culturel du peuple andalous. En guise de préambule de cette analyse-là, on expose quelques aspects géographiques, historiques et linguistiques où le dialecte andalous s'origine ; on détermine les traits phonético-phonologiques qui caractérisent le parler andalous ; on fait connaitre les influences d'autres langues dans ce dialecte, à travers son analyse lexico-sémantique ; on identifie sa morphosyntaxe, spécifiquement, ses différences et ressemblances avec l'espagnol standard ; et on établit, à travers l'analyse textuelle, les marques de cohérence et d'idéologie dans le texte.

Mots clés: dialecte andalous, niveau phonético-phonologique, niveau morphosyntaxique, niveau lexico-sémantique.

\section{Análise de rasgos linguísticos no texto andaluz La infancia de Jesu-Christo desde uma perspectiva sócio-histórica e cultural}

\section{Resumo}

Este artigo mostra a análise linguística de um texto do século XVII intitulado $L a$ Infancia de Jesu-Christo, de Gaspar Fernández e Ávila, mediante a identificação dos rasgos semânticos, morfológicos, léxicos e sintáticos do dialeto andaluz, desde uma mirada sócio-histórica e cultural do povo andaluz. A maneira de preâmbulo de tal análise se expõem alguns aspectos geográficos, históricos e linguísticos nos quais se origina 0 dialeto andaluz; se determinam os rasgos fonético-fonológicos que caracterizam a fala andaluza; se dão a conhecer as influências de outras línguas nesse dialeto, através da análise léxica-semântica da mesma; se identifica sua morfossintaxe, especificamente, suas diferenças e semelhanças com o espanhol standard; e se estabelece, mediante a análise textual, as marcas de coerência e ideologia no texto.

Palavras Chave: dialeto andaluz, nível fonético-fonológico, nível morfossintático, nível léxico-semântico. 
"La identidad andaluza se manifiesta en una cultura compleja, contradictoria a veces, compuesta de elementos beterogéneos que provienen de muy diversos horizontes históricos y culturales; una cultura modeladay remodelada a lo largo de un proceso bistórico singular y diferenciado"

Isidoro Moreno (2008, p. 25)

\section{Introducción}

En esa complejidad cultural, el dialecto andaluz es un elemento diferenciador de extremada importancia porque sugiere un deseo de emancipación de la España central. El andaluz surgió en las postrimerías de la Edad Media como un rasgo particular de los habitantes de una región que geográfica e históricamente tenía unas características diferentes de la España que detentaba el poder, característica que permite abordar un recorrido histórico por el dialecto andaluz, con el propósito de entender e identificar en el campo de la Lingüística, de qué manera se ha dado este proceso y cuál es la panorámica de este sistema dialectal de origen castellano, pero que posee algunos elementos fonéticos, semánticos y sintácticos diferentes de su lengua madre.

Cabe anotar, además, que el andaluz hoy por hoy solo se puede considerar como una variación fonética del castellano, pues generalmente se habla en andaluz, pero se escribe en castellano, razón por la cual es difícil determinar todas las variaciones que revela en un texto escrito. Sin embargo, en este trabajo se presenta un análisis lingüístico de este dialecto con el fin de concederle también el mérito de ser la rama del castellano que llegó a América y que comparte con el español americano rasgos comunes. Para lograr dicho objetivo, se analiza la obra La infancia de Jesu-Christo, de Gaspar Fernández y Ávila1; este texto es considerado como una obra inédita del andaluz, es un poema compuesto por doce coloquios, en donde se puede diferenciar algunos rasgos fonéticos, fonológicos, semánticos y morfosintácticos. En dichos niveles, se realiza el análisis para explicar y contrastar variaciones lingüísticas entre el dialecto andaluz y el español.

\section{Aspectos geográficos, históricos y lingüísticos de Andalucía}

El habla andaluza, o español meridional, es una variedad linguiística que permea todo el sur de la península española, que incluye un conjunto de regiones que se pueden dividir en dos grandes bloques: La Andalucía Occidental y la Andalucía Oriental. La primera

1 Hemos tomado la copia del texto original que reposa en la Biblioteca de Málaga (España). 
comprende las regiones de Cádiz, Huelva, Sevilla y Córdoba; la segunda, Jaén, Granada, Almería y Málaga.

La historia de Andalucía está plagada de un número de invasiones que fueron fundamentales en su constitución: los fenicios (siglo IX a.C.), los griegos (siglo VIII a.C.), los íberos (siglos VI y IV a.C). Los cuales van construyendo, con el transcurrir del tiempo, unas formas artísticas, culturales, idiomáticas y sociales, más o menos homogéneas. Los árabes invaden el sur de la península y se establecen en este territorio hasta el siglo XV d.C. La ocupación árabe es parte fundamental en la constitución de la esencia del pueblo andaluz, puesto que dejaron un gran influjo cultural, artístico y lingüístico en esta zona. Sin embargo, muchas personas continuaron con sus creencias religiosas, sus costumbres y su lengua para distinguirse de ellos. A estos se les denominaron "mozárabes". Hoy día se conocen muchos rasgos del mozárabe, debido a que los propios árabes utilizaban esta "lengua" entremezclada en sus poesías escritas (Moreno, 1977, pp. 35-46).

Durante los siglos XII y XV el reino cristiano se expandió a los territorios ocupados por los árabes en el sur de la península, hecho que permitió reconquistar el territorio y expulsar a los árabes de Andalucía, luego España vivía un ambiente de unificación y, en ese contexto, se unificaron también reglas gramaticales para una lengua común. Pero estos intentos chocaron, puesto que al sur había una vasta región en donde se hablaba de forma diferente al centro del país. Esto ha sido motivo para que se menosprecie y se tienda a relegar el habla andaluza. Ha existido una fuerte tensión entre la región andaluza y la región de Castilla, toda vez que los primeros tienen una cultura y un habla distinta del castellano estándar, lo que se convirtió en la razón para menospreciar y tratar de incultos $\mathrm{y}$ atrasados a los andaluces.

\subsection{El dialecto andaluz}

El nombre de Andalucía se da a partir de la presencia del Islam en el sur de la península proveniente del término andalusí, nombre con el que los árabes denominaron a los territorios ocupados por ellos y dentro de los cuales se encontraba lo que más tarde se conocería con dicho nombre. En cuanto a su dialecto, se le considera como una evolución del castellano llevado por los colonizadores y repobladores, en el siglo XIII, al sur de la península. El rasgo más significativo de esta habla, dentro de la estimación linguística de España, es el "ceceo" y el "seseo"; además, su entonación es más variada y más ágil en un ritmo rápido, una fuerza espiratoria menor y una articulación más relajada y una posición, de todos los órganos articulatorios, dirigida hacia la parte delantera de la boca. (López, 2004, p. 28). 
Pero el dialecto andaluz no quedó resguardado entre sus fronteras, pues ha existido una polémica entre lingüistas sobre su influencia en el castellano hablado en América. Muchos de estos estudiosos coinciden en afirmar la existencia de las estrechas relaciones que hay entre el castellano de América, específicamente en el área del gran Caribe, con algunos rasgos fonéticos, morfo-sintáctico y léxicos del dialecto andaluz, denominando a este fenómeno como "andalucismo".

\subsection{La literatura de Andalucía}

La literatura de Andalucía se encuentra ligada estrechamente a la evolución de la literatura árabe de oriente, de donde fue importada en épocas de conquistas y más tarde por los mismos andaluces que viajaban a oriente en busca de la ciencia. Los andaluces aprendieron pronto los modelos y géneros literarios de los árabes, aportaron la creación de una nueva forma métrica donde se funden elementos populares con la poesía culta: la moaxaja, o poema compuesto de cinco o seis estrofas divididas en dos partes: una con rimas independientes y la otra con rima y estructura iguales a la de la última estrofa. Dentro de esta clase de poemas, se insertaban pequeñas cancioncillas, semejantes a los villancicos, de dos, tres o cuatro versos escritos en lengua romance, llamadas "jarchas" (Martínez, 1999, p. 241).

Una característica de la literatura de esta región es el reflejo aproximado de la realidad idiomática, en tanto que imita rasgos fonéticos, morfo-sintáctico y léxicosemánticos del dialecto andaluz hasta el punto que hay quienes afirman que lo que existe, ante todo, es una literatura andalucista desde el punto de vista lingüístico.

Pasados los siglos y, con una identidad lingüística constituida, los andaluces empiezan a producir sus obras con las características propias de su dialecto, tan es así que todos o casi todos los rasgos fonéticos-fonológicos que pueden registrarse en la escritura y que en su conjunto caracterizan el andaluz, figuran documentados entre los siglos XV al XVII y en el siglo XVIII aparecen ya consolidados. Es a mediados de este siglo, entre 1725 y 1750, cuando se encuentran unos coloquios dramatizados, de ambiente rural, titulados La Infancia de Jesu-Christo, de autoría del cura malagueño Gaspar Fernández y Ávila (Corominas, 1974).

\subsection{Aspectos fonéticos y fonológicos del dialecto andaluz}

El dialecto andaluz presenta rasgos fonéticos y fonológicos característicos que lo diferencian del castellano, entre estos se encuentran: la entonación (más variada y ágil), el ritmo (más rápido y vivaz), una menor fuerza espiratoria, la articulación más relajada y la elevación -hacia la parte delantera de la boca- de la posición de los órganos de 
articulación. Asimismo, el andaluz se caracteriza por 1. La presencia de la /h/ aspirada (fonema inexistente en español estándar) proveniente de los fonemas glotales árabes; 2 . La elisión de consonantes finales (rasgo propio del latín de la Bética); 3. La sustitución de la lateral /// por la vibrante simple /r/ (influencia del tamazigh como sustrato lingüístico); 4 . El yeísmo; 5 . El seseo (pronunciación de 'c, o, z' como /s/); 6. El ceceo (pronunciación de 's' como $/ \theta /)$; 7. La geminación como rasgo fonológico diferenciador, inexistente en otros dialectos de la península y, 8. La existencia de un sistema cuadrangular vocálico, con cinco grados de abertura y dos localizaciones que afectan todo el sistema.

De esta manera, de los dialectos meridionales, el andaluz se destaca por la complejidad que en él presentan sus rasgos fonéticos y fonológicos, entre los que se destacan: la pérdida de las consonantes en posición final (elisión apócope), la pérdida en mitad de palabra o de palabra completa; también es común en la preposición de (elisión total) y para esta última, sufre pérdida de la sílaba final cuando ocupa posición átona. Por ejemplo: voy pa' Sevilla. La pérdida de la oclusiva dental sonora /d/ se presenta en contextos intervocálicos (parador > paraor); en verbos cuyos participios terminan en ído (comío, venío, sabío) y, en posición implosiva (dijo > ijo). El cambio entre líquidas $\Lambda />/ r /$, suelen conservarse muy relajadas o neutralizarse en el cierre vocálico (barcón, carcetín, argún, gorpe); precedidas de consonantes oclusivas, velares o bilabiales (plometió, branco) y, cuando $\mathrm{N} /$ precede a $/ \mathrm{r} /$, a final de palabra (amállos, pagálles). La metátesis consonántica, aunque no es exclusiva del andaluz, es frecuente cuando la sílaba en cuestión comienza con una bilabial oclusiva (sonora o sorda) y la /r/ aparece en posición implosiva o formando grupo con otra consonante; por ejemplo: permitir > premitir, pobre $>$ probe, virgen $>$ vinge'. El cambio e $>$ i en posición átona obedece a múltiples causas, entre las que se cuentan: a) inestabilidad de timbre de la vocal en posición átona; b) proceso de asimilación o disimilación; c) cambio analógico, y d) cruce de palabras o términos. El diptongo ue $>$ güe, la aparición de la velar sonora $/ \mathrm{g} /$ antes del diptongo 'ue' corresponde a un fenómeno propio del español medieval, en el que se presentaba la hipertrofia articulatoria del elemento velar de la /u/. En el caso de bueno > güeno, la /b/ es desplazada debido a un proceso de equivalencia acústica (contacto de dos sonoras).

De igual forma, la pérdida de las consonantes sonoras fricativas intervocálicas -b- > -d- > -g-: La /b/ al ser la más resistente, rara vez es elidida. (ehcoba, amaba, lobo). Por su parte, la /d/ (como se mencionó con anterioridad), sufre elisión en los verbos cuyo participio termina en -ido (salío) y palabras que finalizan en -udo (núo), -uda (pelúa), -ado (lenguao), -ada (posá) y -eda (porvarea); pero se conserva en voces con escasa entidad fonética (codo, pudo, boda). Al igual que la /b/, la /g/ es muy resistente, se conserva cerca 
de diptongos y en palabras bisílabas, mientras que se pierde si precede a una sílaba tónica seguida de velar (migaja > miaja). La aspiración de la /r/ ante nasal, cuando la vibrante se encuentra en posición implosiva y la velarización de la alveolar nasal sonora $/ \mathrm{n} /$.

En relación con los aspectos articulatorios, la /s/ se presenta con distintos rasgos, según la región geográfica: en el extremo Norte de Huelva, los Pedroches, Este de Jaén, Norte de granada, Almería, Extremadura, Castilla la Nueva y Murcia subsiste la ápicoalveolar /s/; en el resto de Andalucía se presenta la 'coronal' /s/ y la predorsal /s/, siendo esta última la que caracteriza la dicción andaluza.

Asimismo, es peculiar la relajación de la africada palatal sorda /ĉ/, la cual se despoja de su oclusión inicial y se convierte en /š/ (/nóše/), fenómeno extendido por la costa de Almería, Granada, occidente de Málaga, Cádiz y el sur de Sevilla. Este cambio, sumado al yeísmo, permite que el andaluz (en sus estadios más evolucionados) simplifique los fonemas palatales castellanos $(/ \hat{\mathbf{c}} /, / \mathrm{\Lambda} /, / \mathrm{y} /)$ reduciéndolos a la pareja homogénea $/ \check{s} /(<$ $/ \hat{\mathbf{c}} /)$ y $/ \tilde{z} /(</ / \mathrm{y} / \mathrm{y} /)$.

\section{Metodología}

El presente trabajo se enmarca en la investigación cualitativa-descriptiva, pues se hace una interpretación de un documento escrito La Infancia de Jesu-Christo que, desde lo planteado por Lupicinio Iñiguez (2006), está constituido por enunciados que muestran una posición determinada, inscritos en un contexto interdiscursivo específico y revelador de condiciones históricas, sociales e intelectuales que poseen un valor para una colectividad, implicando creencias y convicciones compartidas.

La infancia de Jesu-Christo es un poema dramático dividido en doce coloquios, fue elegido como corpus del presente estudio, debido a la riqueza histórico - geográfica y a la variación lingüística que presenta frente a la lengua española. En él se puede realizar el análisis del dialecto andaluz en el nivel fónico-fonológico, morfosintáctico y léxicosemántico. Para este trabajo se eligió, al azar, como muestra sólo un fragmento que hace referencia a un diálogo entre un personaje femenino y uno masculino. Se seleccionan las grafías, las palabras y el discurso bajo rasgos distintivos sociolingüísticos de las variaciones del español para el análisis propuesto. Se realiza una descripción de los aspectos lingüísticos del dialecto andaluz, se comprueba con el texto los rasgos más relevantes, luego se procede al análisis descriptivo para mostrar los resultados y las conclusiones. 


\section{Análisis lingüístico de La Infancia de Jesu-Christo” (Fernández y Ávila)}

\section{TRANSCRIPCIÓN (RFE $\left.{ }^{2}\right)$}

El texto se caracteriza porque está escrito, en su mayor parte, en andaluz. La primera edición de este documento data de 1784 . El texto se divide en doce coloquios, es un poema dramático, por lo tanto se sucede en diálogos, y a través de ellos nos cuentan la historia de los primeros años de Jesús desde su encarnación hasta el momento en que el niño entra al templo.

3.1 Nivel fonético-fonológico: pese a la frecuente elisión de consonantes en posición final del andaluz actual, a lo largo de los doce coloquios del poema no se evidencia este fenómeno. En contraste, se observa:

\section{Pérdida de palabra completa (preposición)}

Tras de mi $>[-$ de- $]>[-\varnothing-]$

$$
>\operatorname{tras} \mathrm{mi} \quad / \text { trasmi// }
$$

b. Pérdida de mitad de palabra

$$
\begin{aligned}
\text { Adelantillo } & >[-\mathrm{de}-]>[-\varnothing-] \\
& >\text { alentillo /alãņtílo/ }
\end{aligned}
$$

De la misma manera, en el texto de Gaspar Fernández, se evidencia la pérdida de la oclusiva dental sonora /d/:

a. En contexto intervocálico

$$
\begin{array}{rlll}
\text { Delicado } & > & {[-\mathrm{d}-]>[-\emptyset-]} \\
& > & \text { delicao /delikáo/ } \\
\text { miedo } & > & {[-\mathrm{d}-]>[-\emptyset-]} \\
& > & \text { mieo /mjéo/ }
\end{array}
$$




$$
\begin{aligned}
& \text { queda }>\quad[-\mathrm{d}-]>[-\varnothing-] \\
& >\text { quea /kéal } \\
& \text { ganado }>\quad[-d-]>[-\varnothing-] \\
& >\text { ganao /gãnão/ } \\
& \text { todos }>\quad[-\mathrm{d}-]>[-\varnothing-] \\
& >\text { toos /tōs/ }
\end{aligned}
$$

b. En posición implosiva

$$
\begin{array}{rrrr}
\text { dijo } & > & {[\mathrm{d}-]>[-\varnothing-]} \\
& > & \text { ijo } & \text { /íxo/ }
\end{array}
$$

Asimismo, se presenta neutralización entre líquidas $/ \mathbf{l}>/ \mathbf{r} /$, en:

a. Cierre vocálico

$$
\begin{array}{lll}
\text { Cuerpo } & > & {[-\mathrm{r}-]>[-1-]} \\
& > & \text { cuelpo /kwélpo/ } \\
\text { perverso } & > & {[-\mathrm{r}-]>[-1-]} \\
\text { pelverso } & > & {[-\mathrm{r}-]>[-1-]} \\
& > & \text { pelvelso /pelbélso/ }
\end{array}
$$

b. Precedida de la consonante bilabial oclusiva sonora /b/

$$
\begin{array}{rll}
\text { Pueblos } & > & {[-\mathrm{r}-]>[-1-]} \\
& > & \text { puebros/pwébros/ }
\end{array}
$$

c. Al final de palabra, cuando la $/ \mathbf{r} /$ precede a $/ \mathbf{~}$, la vibrante se convierte en consonante lateral /11/:

$$
\begin{aligned}
& \text { Apretarlo }>\quad[-\mathrm{r}-]>[-1-] \\
& >\text { apretallo /apretálo/ }
\end{aligned}
$$

Con respecto a la metátesis consonántica, esta se presenta cuando la consonante bilabial oclusiva sorda /p/ (en posición implosiva), precede a la alveolar vibrante simple $/ \mathbf{r} /$ :

$$
\text { Portento > protento /proté to/ }
$$


Del mismo modo, es recurrente el cambio de/e/ > /i/ (en posición átona), resultado -entre diversos factores- de cierta inestabilidad en el timbre de la vocal átona:

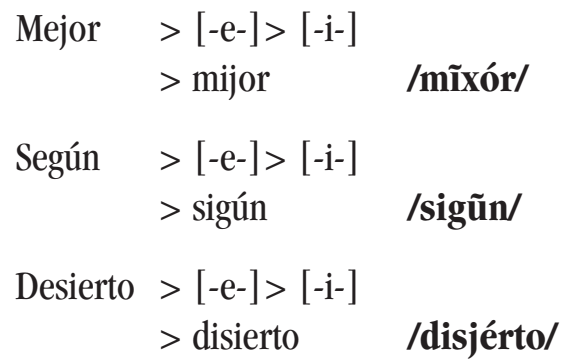

Finalmente, como fenómeno propio del español medieval, aparece la consonante oclusiva velar sonora /g/ antes de /we/:

$\begin{array}{rlll}\text { Hueso } & > & {[\emptyset-]>[\mathrm{g}-]} \\ & & >\quad \text { güeso /gwéso/ } \\ \text { bueno } & > & {[\mathrm{b}-]>[\mathrm{g}-]} \\ & > & \text { güeno } & \text { /gwéno/ }\end{array}$

3.1.1 El acento: cualquiera de nosotros ha oído que el pueblo intenta caracterizar la manera de hablar de la gente que practica una variedad de lengua o una lengua estándar por medio de los conceptos: acento, deje o tonillo, pues bien, el acento es el conjunto de particularidades fonéticas, rítmicas y melódicas que caracterizan el habla de un país, región o ciudad. Y esto precisamente, es lo que marca la diferencia frente a otros grupos de hablantes de las regiones de España.

\subsubsection{El consonantismo}

3.1.2.1 El ceceo: cecear es el pronunciar la/s/con la articulación igual o semejante a la de la /c/ ante /e/, /i/ o a la de la /z/, definición que en sustancia ya viene de antiguo. El ceceo consiste en la desfonologización de la oposición /s/:: / $/ \theta /$ del español normativo, existente también en extensas zonas del norte de la Andalucía administrativa; consiste, por lo tanto, en la eliminación del fonema /s/ y la utilización exclusiva del dentointerdental andaluz $/ \Theta /$, con lo que los pares mínimos del español general y culto de casa / caza, basa / baza, tasa / taza, quedan reducidos a caza, baza, taza, entre otros; en estos casos, es el contexto el que descubre el significado de cada una de las modalidades léxicas utilizadas. 
Esquema diacrónico del origen del çeçeo / zezeo y del ceceo / seseo

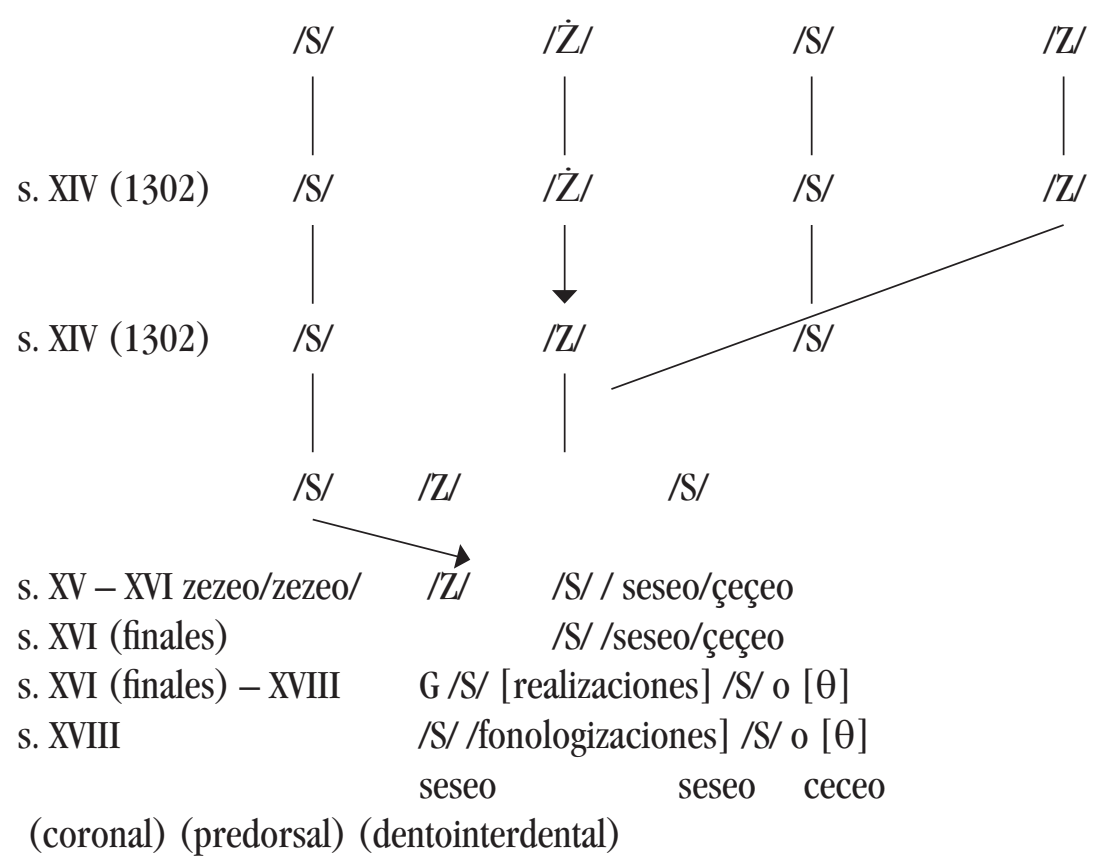

Fuente: Mondéjar (1991, p. 44)

3.1.2.2 La aspiración: podríamos definir el rasgo de la aspiración como la fuerza con que se emite el aire proveniente de los pulmones en estado totalmente abierto del canal articulatorio. Toda consonante que vaya en posición implosiva puede aspirarse en el dialecto andaluz, el rasgo de la aspiración de la /h/ inicial procedente de la/f/latina: f - > h-: se reemplaza la /h/ por la pronunciación gutural de /j/, como jembra por hembra, jierro por hierro. De igual forma, se da la aspiración de la /s/ tanto en posición intervocálica como en posición final absoluta, como por ejemplo:

Camará, nojotros no necesitamos jeso!

Qué le jace si es más largo.

Qué delicao se se ha hecho.

$Y$ te jaces un veneno.

3.1.2.3 El yeísmo: pronunciación de la elle /1/ como ye /y/; ejemplo: //gayina// en lugar de //gallina//; //poyo//, por //pollo//. Se trata de una tendencia fonética natural que convierte un fonema palatal lateral sonoro en el palatal central correspondiente. La documentación andaluza del yeísmo se encuentra muy esporádica y dispersa en los 
escritos de los siglos XVI y XVII. Es a partir del XVIII cuando se generaliza su aparición en los papeles de archivo y en las manifestaciones populares literarias. Parece ser un síntoma claro de que en la primera mitad del siglo XVII todavía no debió darse el yeísmo en la Andalucía occidental (Mondéjar, 2001, p. 194).

3.1.2.4 El vocalismo: el vocalismo andaluz oriental es el más curioso del español de hoy. Al respecto, Salvador (1977, p. 1) afirma: "Precisamente por afectar en toda su extensión al sistema vocálico castellano, modelo entre los modelos, tipo básico del vocalismo triangular de cinco unidades, perfectamente diferenciadas y sin mixturas", entonces, podría decirse que la aspiración de la /s/ ( $0-z)$, sería el fenómeno que había producido una abertura en la vocal anterior y que, perdida la aspiración, esta abertura ha heredado su función diferenciadora, generalmente morfológica (flexión nominal, flexión verbal).

Desde el punto de vista histórico, la existencia en andaluz oriental de vocales abiertas con valor distinguidor, tanto en el plano léxico como en el gramatical, se debe al especial tratamiento que las consonantes /j/, /s/. / / / . /r/ y // sufren en posición final. La articulación aspirada de estos sonidos, con la siguiente abertura mecánica de la vocal precedente, y su eliminación final, permite que oposiciones léxicogramaticales del español, del tipo //perdí// - \{perdíz\}, //clavé//- \{clavel\}, //amó//- \{amor\}, //dio//- \{dios\}, entre otros, se realizan en el andaluz a base de la distinción existente entre vocal media y vocal abierta. Así mismo, se presentan alargamientos; veamos estos versos:

También estóo yo lo mesmo.

Está la majáa, Rebeca.

Porque ya estó muu cansáa.

3.2 Nivel morfosintáctico: la estructura morfosintáctica del habla andaluza permanece sustancialmente inalterada, porque lo que verdaderamente se aleja del español culto y común pertenece al plano de la fonética y la fonología. Los recursos flexionales que pueden parecer propios no son más que arcaísmos o resultado de profundos cambios fonéticos.

\subsubsection{Morfología andaluza}

3.2.1.1 Flexión nominal, el género: la oposición de género se establece en español, de modo general, por medio de los morfemas de flexión /o/ /a/: niñ-o/niñ-a, salvo casos excepcionales o de distribución inconexa social y geográfica. Veamos algunos ejemplos: 
Tabla 1. Flexión nominal: género y contexto geográfico

\begin{tabular}{|l|l|l|}
\hline \multicolumn{1}{|c|}{ GÉNERO MASCULINO } & \multicolumn{2}{c|}{ FEMENINO } \\
\hline Málaga & Peste, rebeca, jersey, viena, pan. & Mar, \\
\hline Baeza & Chinche, dote, alpargate & Mimbre, linde, susiambre, mugre, calor \\
\hline Cullar-Baza & Chinche, dote, & Mar, olivo \\
\hline Lepe & Gripe, cerillo & Calor, mar \\
\hline Córdoba & Tizne & Mar, reuma \\
\hline Jaén & Tizne & Mar, risca \\
\hline Granada & Tizne & Mar, pus \\
\hline Almería & Tizne & Mar, pandera \\
\hline
\end{tabular}

Fuente: Mondéjar (2001, p. 40)

3.2.1.2 Flexión verbal, los morfemas flexionales: según un estudio de Menéndez Pidal (1980, p. 324), La /s/ en posición implosiva final absoluta actúa en español indistintamente tanto de morfofonema de flexión nominal de número como de flexión verbal de persona. En consecuencia, la aspiración resultante de la misma y la apertura vocálica, cuando la aspiración ha desaparecido, desempeñan idéntica función en andaluz. La antigüedad de este fenómeno no es tanta. Aun suponiendo que en el primer tercio del siglo XVI ya se diera el proceso $-s b$ - $>-b b->-f$ - sería, igual que ahora lo es, un fenómeno del estrato sociocultural ínfimo, rural y suburbial. Ejemplos:

Resbalar: Refalar.

Transbordar: Trafordar.

3.2.1.3 Pronombre personal: la pérdida de la /s/ de la segunda persona del singular de todos los tiempos, menos del pretérito perfecto simple y del imperativo, que etimológicamente carecen de ella, se da la de la /n/ de la tercera persona del plural, y, a veces, de la $/ \mathrm{r} /$ del infinitivo.

Lo más llamativo es la casi sustitución de vosotros por ustedes, en toda la Andalucía. Así, en muchos sitios, el pronombre de segunda persona del plural es ustedes, sin que el verbo haya unificado las personas segunda y tercera (ustedes vais) o confundiendo ya ambas (ustedes vinieron 'vosotros vinisteis', ustedes vinieron 'ellos vinieron').

3.2.1.4 Acentuación: en la conjugación se destaca, en el oeste, el gran arraigo y la extensión de los desplazamientos acentuales: háyamos, háyais, véngamos, véngais, sálgamos, sálgais, ríamos, ríais, etc. La acentuación vácio, etc., está muy generalizada. En 
cambio, se dan más en la Andalucía oriental, sobre todo en Jaén y Granada, las desinencias -éis por-ís-(venéis, saléis), con algún-is por-éis (querís, ponís). También se extiende por la región oriental, incluso, por Córdoba la acentuación escogiámos, escogiáis en los imperfectos.

3.2.1.5 Verbos: se encuentran imperfectos del tipo traiba o perfectos arcaicos y vulgares como vide y vido, del verbo ver; truje y trubo, del verbo traer. Respecto de los morfemas de flexión del pretérito perfecto, dominan en toda Andalucía, los de la segunda persona del plural, pues el hablante utiliza en distintos puntos y estratos, las desinencias -ates, -atis -ites,-itis (matates/matatis, comites/comitis). El más arcaico -ate, -ite 'astes', 'istes'.

En los llamados verbos irregulares de la primera conjugación, el lexema de andar ofrece en el pretérito perfecto simple andé y andó, analógicas de amé y amó; a veces se iguala todo el paradigma: anduve, andate, andó, andamo, andati, andarõ. Los sufijos más extendidos son -ico, illo y repeticiones intensificativas como iyiyo.

\subsubsection{Aspectos morfosintácticos en La Infancia de Jesu-Christo}

En el texto encontramos elementos morfosintácticos propios del castellano, recordemos que es un dialecto del español, de igual manera, el andaluz evidencia sus diferencias en el aspecto fónico, ya que la escritura generalmente es en castellano, con sus mismas formas gramaticales: sustantivos, adjetivos, verbos, adverbios, conjunciones, artículos, pronombre y preposiciones.

En el texto encontramos varios casos particulares de la morfosintaxis andaluza, que difieren del castellano, como por ejemplo: "Tal", es un adjetivo usado aquí como un nombre propio: Talaquel; sin embargo, acompañando a otros sustantivos significa tan, como en "tal pergeño", "tal pelvelso". "Le": pronombre personal, forma de dativo singular de tercera persona singular en masculino o femenino (Le ría). "Mos": es usado en el texto, solo una vez, como la primera persona del plural, conocida en castellano como "nosotros" (nos). "En": es una preposición y en este caso significa luego que, después que.

3.3 Nivel léxico-semántico: el aspecto léxico-semántico del dialecto andaluz es una gran complejidad, debido a que ha recibido préstamos lingüísticos de lenguas y dialectos con los cuales convive o convivió en el pasado. Como ya se explicó, la cultura árabe tuvo una gran influencia en el andaluz. Andalucía fue la tierra donde los árabes permanecieron desde el siglo VII hasta finales del siglo XV e impregnaron la zona de muchos vocablos (Moreno, 1977, p. 23); entre otros tenemos: 
Tabla 2. Influencia árabe

\begin{tabular}{|l|l|}
\hline \multicolumn{1}{|c|}{ INFLUENCIA DEL ÁRABE } & \multicolumn{1}{c|}{ SIGNIFICADO } \\
\hline Alfaran & "insecto" \\
\hline Cefri & "parte inferior del horno" \\
\hline Atarfe & "piedra inferior del molino" \\
\hline Aljofifa & "estropajo" \\
\hline Hamal & "pajarito" \\
\hline
\end{tabular}

Fuente: Mondéjar (2001, p. 31)

La influencia árabe en la lengua española ha sido característica, específicamente, en el nivel léxico, que se explica por la expansión arabófona en Hispania y la península Ibérica en los años 711 y 1609. La influencia arabófona fue más patente en el sur y este de su territorio, en la actual Andalucía. Como resultado se encuentran aún: topónimos, sustantivos y nombres propios, pocos verbos, algunos adjetivos y adverbios y una sola preposición: "hasta"; lo cual puede reflejar que la influencia, siendo amplia y muy importante, no consiguió variar la estructura romance del idioma. En el léxico andaluz también se encuentran numerosos arcaísmos de origen castellano, tales como:

Tabla 3. Arcaísmos castellanos

\begin{tabular}{|l|l|}
\hline \multicolumn{1}{|c|}{ ARCAISMOS CASTELLANOS } & \multicolumn{1}{c|}{ SIGNIFICADO } \\
\hline aqueste, aquesta, aquese, aquesa & Aquel, aquella, aquello, aquella. \\
\hline Mueso, muesa & Muestre, muestra \\
\hline Ataute & "aglomeración de gente" \\
\hline Manque & "aunque", \\
\hline Atacarse & "abotonarse" \\
\hline Desmonterarse & "quitarse el sombrero" \\
\hline
\end{tabular}

Fuente: Mondéjar (2001, p. 32)

Otro préstamo semántico que se puede apreciar en el territorio Andaluz son las palabras mozárabes. Los mozárabes estuvieron en Andalucía occidental, concretamente en Sevilla, agregaron términos como: cauchil: 'arca de agua'; almatriche: 'reguera'; Paulilla: 'insecto dañino' para los cultivos, en castellano significan cauce, madriz y polilla respectivamente. Algunos préstamos léxicos provienen del pueblo gitano, nómadas, con una cultura particular, su lengua se denomina caló, de ella provienen vocablos como: 
Currar: 'trabajar'; Gili: 'bobo'; canguelo: ‘miedo'; Menda: 'yo'; Pirarse: ‘irse'; Jalar: 'comer'. (Corominas, 1974).

Pero la convivencia del andaluz y el caló no solo han influido en el lenguaje, sino en las costumbres, fiestas y diversiones. Desde mediados del siglo XIX, el gitanismo se fue apoderando de ellas. Los toros, los "cafés cantantes" y hoy día, los festivales de flamenco son una prueba de ello. Esta influencia gitana no solo afecta al andaluz, sino a todo el español. Está confirmado por publicaciones como: "El léxico caló en el lenguaje del canto flamenco" (Ropero, 1978, p. 67) y "Estudios sobre los gitanismos del español" (Clavería, 1951, p. 53). El complejo fenómeno conocido como el flamenco permeó todas las capas de la sociedad española e incorporó al lenguaje español un cuantioso caudal de origen gitano.

A continuación, registramos los préstamos léxicos que aparecen en el primer coloquio del texto La infancia de Jesu-Christo:

Tabla 4. Préstamos léxicos en La Infancia de Jesu-Christo

\begin{tabular}{|l|l|l|}
\hline ANDALUZ & \multicolumn{1}{|c|}{ ORIGEN } & \multicolumn{1}{c|}{ SIGNIFICADO } \\
\hline Barbecho & Latín Vervactum & Campo arado sin sembrar \\
\hline Pollino & Latín pullas & Pollo de gallina \\
\hline Sende & Latín semitarius & Aplícase a la persona que iba por sendas o callejones \\
\hline Mayorazgo & Latín major & Grande \\
\hline Majaa & Latín macula & Lugar donde se albergan de noche el ganado y los pastores \\
\hline Zagal & Árabe zagall & Pastor \\
\hline Zaguero & Árabe saga & Último \\
\hline Engullen & Latín: gula, catalán: engolir & Comer en exceso \\
\hline Apero & Latín appariare & Enjaezar el caballo \\
\hline Brena & Portugués brenha & Lugar fragoso, tierra quebrada entre penas y poblada de maleza \\
\hline Pergeno & Latín pergenium & Apariencia \\
\hline
\end{tabular}

Fuente: Autoras

En los ejemplos expuestos, encontramos un campo semántico que alude a la zona rural. Se hace evidente en el uso de palabras cuyo significado se refiere al campo, lugar de pastoreo, lo cual muestra que los personajes del texto pertenecen al campesinado de la región andaluza, que se dedican a las labores campestres, a cuidar el ganado, a sembrar, etc. 


\subsubsection{Campos semánticos}

La historia narrada en La Infancia de Jesu-Christo tiene como escenario la región rural de Andalucía, y todos los personajes son pertenecientes a esta comunidad local, los dos primeros coloquios abordan la encarnación del hijo de Dios, mediante los diálogos de tres pastores (dos hombres y una mujer).

Dentro de las particularidades del texto, encontramos que los personajes centrales de esta historia, la virgen María, José y el ángel San Gabriel, hablan en castellano, los pastores o la gente de la comarca son los únicos a quienes se les registra el habla andaluza, esto nos muestra que desde esa época existe la idea de que el andaluz es un dialecto de las clases sociales bajas o incultas, y aunque el texto fue escrito por un andaluz, es interesante anotar que aun para los lugareños, esta es una idea aceptada. De ahí parte la discriminación hacia esta forma de habla que difiere, en el aspecto fonético, del español estándar. Hecho que aún hoy no pierde vigencia, pues los madrileños se consideran muy por encima de los andaluces, los discriminan por su habla y porque descienden directamente de los árabes.

Por otro lado, se observa también que en el texto se recrea la vida del campo de la época, en la región de Andalucía; los pastores se dedicaban a cuidar del ganado de sus amos, y a las tareas propias de la tierra. Se hace mención a las tierras no aradas, a aquellas que estaban llenas de maleza, lo que nos permite inferir que, por aquel entonces, la región poseía extensiones de tierra virgen, sin explotar (versos 1, 3, 4).

Las clases sociales también se identifican aquí, como en el momento en el que Josef, el pastor, cuenta a Rebeca cómo es la vida y el trabajo con su nuevo amo. Esta es una descripción del sistema feudal imperante en la época; el Señor, quien era dueño de las tierras, y ejercía el "mayorazgo" en la región, era una persona muy adinerada y poderosa, a él se le trabajaba, y a cambio proveía alimentos, bienestar y estabilidad socioeconómica (versos 21-25).

El texto también hace mención, en la primera parte de la conversación entre los dos pastores, Josef y Rebeca, a la opinión que los hombres tenían de la mujer y viceversa. Para los hombres de Andalucía, las mujeres son muy perversas, hay que dominarlas y tenerlas vigiladas; y las mujeres piensan que hay que renegar de los hombres, pues todos son groseros (versos 7-20). 


\section{Conclusiones}

Para realizar el estudio de una lengua y sus variaciones es necesario partir de la lengua como sistema de signos y de la historicidad, la cual se convierte en un rasgo fundamental en el momento de realizar su función comunicativa.

La modalidad del habla andaluza manifiesta diversas variaciones del castellano, se caracteriza por la elisión de vocales, el acento y la aspiración a nivel fónico- fonológico, el ceceo o zezeo y el yeísmo en el nivel léxico. De igual forma, en el aspecto semántico, a partir de la situación geográfica y cultural, se infiltraron diferentes vocablos como: 'alfara'insecto, 'hamal' - pajarito, 'aljofita'- estropajo, entre otros.

En el texto La infancia de Jesu-Christo, se encontraron aspectos morfosintácticos propios del castellano que, aunque es un dialecto del español, el andaluz muestra diferencias en su forma fónica, y la escritura mantiene las mismas características gramaticales: sustantivo, verbo, adverbio y conjunciones, entre otras categorías.

Finalmente, se puede decir que aunque se extrajo tan sólo un corto fragmento del documento que consta de 318 páginas, se pudo observar una panorámica general de los principales rasgos que determinan la particularidad del dialecto andaluz. Se evidencia en esa muestra escrita una perspectiva del pasado, un intento por conservar los orígenes de un habla singular, a la que los hispanoamericanos le debemos mucho.

\section{Referencias Bibliográficas}

Alvar, M. (1996). Manual de Dialectología. Madrid: Ariel.

Clavería, C. (1951). Estudios sobre los gitanismos del español. C. S. I. C. Revista de Filología Española. Base bibliográfica. Madrid: Universidad de Murcia. Recuperado de http://digitum. um.es/jspui/bitstream/10201/6542/1/N\%204\%20Carlos\%20Claveria.\%20ESTUDIOS\%20 SOBRE\%20LOS\%20GITANISMOS\%20DEL\%20ESPANOL.pdf, pp. 715-717.

Corominas, J. (1974). Diccionario Etimológico de la Lengua Castellana. Madrid: Gredos.

Fernández y Ávila, G. (1992). La Infancia de Jesu-Christo. Málaga: Wagner.

García de Diego, V. (1978). Dialectología Española. Centro interamericano de Cooperación. Madrid: Cultura Hispánica.

Garrulo, T. (1998). La Literatura árabe de Al-Andaluz durante el siglo XI. Madrid: Hiperion. 
Lapesa, R. (1980). La Aventura del Español de América. Madrid: Espasa-Calpe.

López Falcón, José (2004). Lengua Española. Comentario de texto. España: MAD.

Martínez Lorca, Andrés (1999). Ensayos sobre la filosofía en AL-ANDALUS. Una aproximación bistórica. Barcelona: Arthropos.

Menéndez Pidal, R. (1968). Sevilla frente a Madrid: algunas precisiones sobre el español de América. La Laguna: Universidad de La Laguna.

Mondéjar, J. (1991). Dialectología Andaluza. Universidad de Málaga: Analecta Malacitana.

Moreno, I. (1977). Andalucía: subdesarrollo, clases sociales y regionalismos. Madrid: Manifiesto.

Salvador, G. (1977). Unidades fonológicas vocálicas en el andaluz oriental. Recuperado de http://www.sel.edu.es/pdf/ene-jun-77/Salvador.pdf

Sánchez, R. (2001). Historia Breve de Andalucía. Madrid: Siles.

Ropero, M. (1978). El léxico caló en el lenguaje del canto flamenco. Sevilla: Secretaría de Publicaciones de la Universidad de Sevilla. 